\title{
Autosomal dominant intermediate Charcot-Marie-Tooth disease type C
}

INSERM

\section{Source}

INSERM. (1999). Orphanet: an online rare disease and orphan drug data base. Autosomal dominant intermediate Charcot-Marie-Tooth disease type C. ORPHA:100045

Autosomal dominant intermediate Charcot-Marie-Tooth disease type $\mathrm{C}$ is a rare hereditary motor and sensory neuropathy characterized by intermediate motor median nerve conduction velocities (usually between 25 and $60 \mathrm{~m} / \mathrm{s}$ ). It presents with moderately severe, slowly prog ressive usual clinical features of Charcot-Marie-T ooth disease (muscle weakness and atrophy of the distal extremities, distal sensory loss, reduced or absent deep tendon reflexes, feet deformities, extensor digitorum brevis atrophy). Findings in nerve biopsies include age-dependent axonal degeneration, reduced number of large myelinated fibres, segmental remyelination, and no onion bulbs. 